\title{
Emerging Agriculture Applications of Silver Nanoparticles
}

\author{
Sonali K. Kale, ${ }^{1,}{ }^{*}$ Gajanan V. Parishwad, ${ }^{2}$ Avesahemad S. N. Husainy ${ }^{3}$ and Aishwarya S. Patil ${ }^{4}$
}

\begin{abstract}
Agriculture farming is the foundation of most developing economies, roughly $60 \%$ of the population relies on agriculture. The Indian farming division represents $18 \%$ of India's total national output and gives work to $50 \%$ of the workforce of the nation. Research areas like crop disease detection, soil quality improvement, nano-fertilizers and seed germination are still focused areas and researchers are attracted to them. To deal with this fascinating sector, nanotechnology which is an interdisciplinary research field is providing a platform. For example, advancement in nano-fertilizers, which are having high absorption efficiency into the targeted plant due to high surface-to-volume ratio. By using phosphorus nano-fertilizers, absorption efficiencies of up to $90.6 \%$ were achieved. Another beneficial aspect of using nano-fertilizers is the ability to provide a slow release of nutrients into the plant over a period of 40-50 days, rather than the 4-10 days period of conventional fertilizers. In the present article, we have briefly discussed the application of nanotechnology from an agricultural perspective. Herein, we have summarized the applications of silver $(\mathrm{Ag})$ nanoparticles in agriculture such as crop productivity, crop disease detection, food packaging, soil quality, etc.
\end{abstract}

Keywords: Nanotechnology; Silver nanoparticles (AgNP); Crop Productivity; Applications in Agriculture.

Received: 08 December 2020; Accepted date: 12 March 2021.

Article type: Review article.

\section{Introduction}

The obvious basic needs of human beings include food, shelter, clothing, and medicines, etc. Agriculture is one of the major sectors that provide food for humans, indirectly or directly for other needs too. The ever-increasing population results in the increase of demand for all above tremendously, despite the constant availability of natural resources from farming. Therefore, it is of utmost importance to pay particular attention to exploring knowledge in the agriculture sector and utilization of emerging technology for effective crop production. Although, the agriculture sector also adopted technology-based farming termed "smart farming", still there is scope to pursue research on this for betterment. Agricultural production faces the challenge of enhancing crop production and providing nutritionally adequate diets for the increasing population, under uncertain climatic extremes, water scarcity, limited (and degraded in many places) land area, and mostly

\footnotetext{
${ }^{I}$ Department of First Year Engineering, Pimpri Chinchwad College

of Engineering, Pune, Maharashtra, India.

2 Pimpri Chinchwad College of Engineering, Pune, Maharashtra, India.

${ }^{3}$ Shivaji University, Kolhapur, Maharashtra, India.

${ }^{4}$ Department of Technology, SPPU, Maharashtra, Indian.

*Email: sonalikale6@gmail.com (S. Kale)
}

poor-quality water and air, associated with rapid changes in natural biodiversity. To address these problems, there is a need to explore one of the frontier technologies such as 'Nanotechnology' to develop smart ways that promote crop productivity while ensuring environmental safety and higher use efficiency.

Nanotechnology deals with the particles at nanoscale (1$100 \mathrm{~nm}$ ) dimensions. Microscale materials when reduced to the nanoscale exhibit distinguishing properties due to quantum confinement. ${ }^{[1]}$ The size-dependent properties of nanomaterials lead to unique applications. Nanoscience has brought a revolution in potential fields by developing processes and products that are hardly possible to evolve through conventional methods. The nanotechnology aided applications have the potential to change agricultural production by allowing better management and conservation of inputs for plant and animal production. In the agricultural sector, it could be used for insect pest management through the formulations of nanomaterials-based pesticides and insecticides, enhancement of agricultural productivity using bio-conjugated nanoparticles (encapsulation), especially for slow release of nutrients and water, nanoparticle-mediated genes, and for preparation of a variety of biosensors for precision farming. The application of nanotechnology to the agricultural and food industries was first addressed by a 


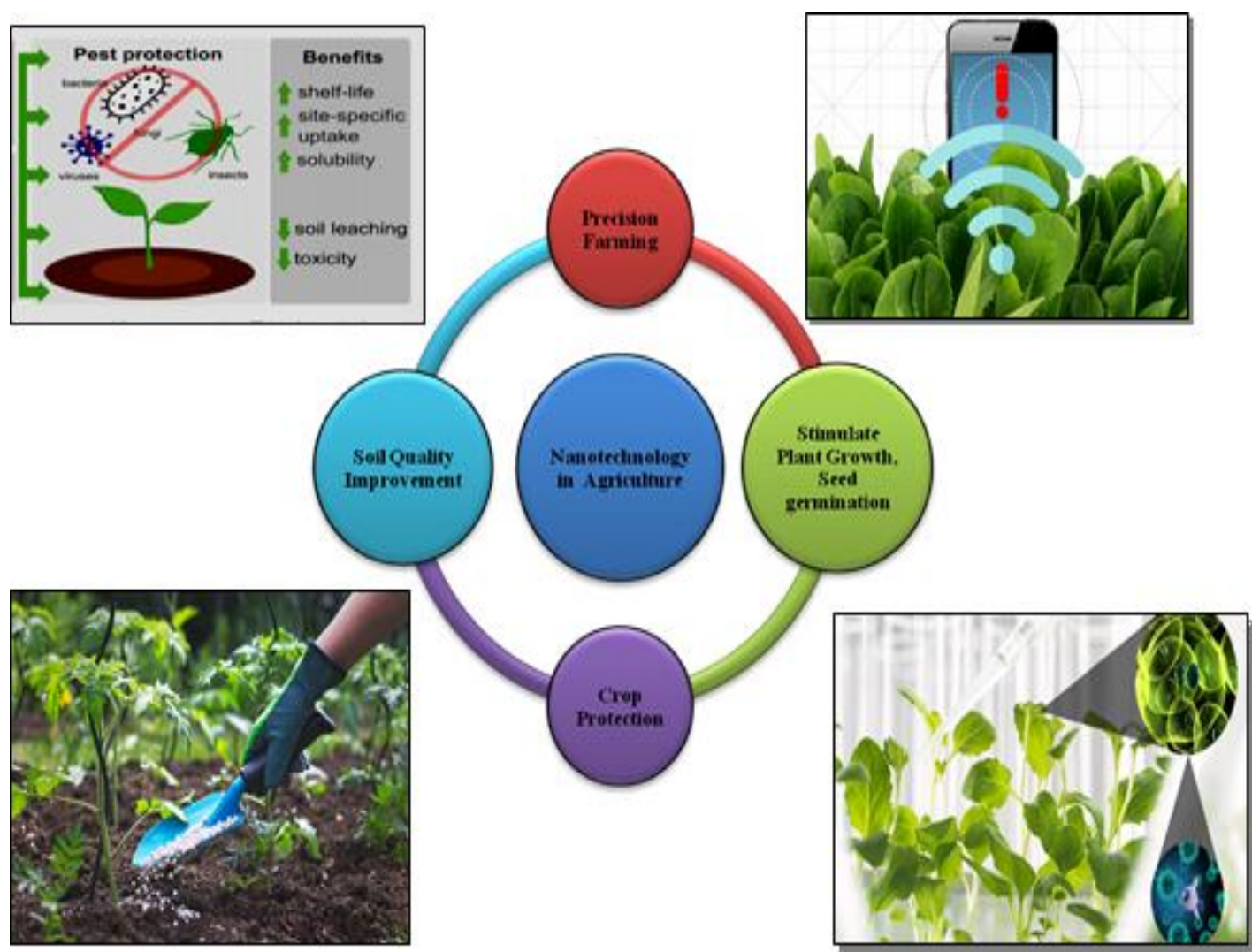

Fig.1 Applications of nanotechnology in agriculture (reproduced with permission from [12], copyright 2016 the author(s), [5] copyright Taylor \& Francis, and [10] copyright 2012 springer science).

United States Department of Agriculture roadmap published in September 2003. ${ }^{[2]}$ The use of nanotechnology in agriculture has been mostly theoretical but it has begun and will continue to have a significant effect in the main areas of agriculture development by using new functional materials, product development, instrumentation for food safety and bio-security in an effective manner. ${ }^{[3]}$

Researchers have already shown increased crop productivity using nanomaterials in numerous ways. The agricultural scientists were attracted to the revolution by nanomaterials. Silver nanoparticles as antifungal and antibacterial agents have a role in agricultural crop protection where these particles also regulate proper nutrition to plants. ${ }^{[4]}$ Nanosensors utilizing carbon nanotubes or nano-cantilevers are small enough to trap and measure individual proteins or even small molecules. ${ }^{[5]}$ Zinc oxide nanoparticles $(25 \mathrm{~nm}$ mean particle size) promoted seed germination, seedling vigor, and plant growth and proved to be effective in increasing stem and root growth in peanuts. A research group at the University of Leeds in the UK has determined that nanoparticles of magnesium oxide and zinc oxide are highly effective at destroying microorganisms and could be used in food packaging. ${ }^{[6]}$ Research is carried out on the application of $\mathrm{Fe}$, $\mathrm{Ag}, \mathrm{Mn}, \mathrm{Zn}, \mathrm{Cu}, \mathrm{Mo}$, Ti and carbon nanotubes as nanofertilizers and nano-pesticides to improve plant growth as well plant protection. ${ }^{[7]}$ Thus it can propose that the appropriate innovations in the applications of nanomaterials in agricultural sector would be challenging phenomena in future and has the potential to revolutionize agricultural and food production as well as helps to maintain the sustainability of agricultural products in a proper way. Fig. 1 shows the various applications of nanotechnology to the agriculture field.

In this context, the present articles summarized on the applications of silver nanoparticles (Ag NP) in pest control, crop improvement, detection of plant diseases and food packaging. To proceed with the applications of $\mathrm{Ag} \mathrm{Np}$, the preparation of these particles has to be carried out in a more systematic way. Silver nanoparticles can be synthesized using physical, chemical and biological methods. Owing to the requirement of extreme conditions and toxic chemicals in physical and chemical methods, biological methods are widely used. Being single step synthesis and ecofriendly, different researchers have synthesized silver nanoparticles from different sources like plant extracts, bacteria, fungi, etc. ${ }^{[8]}$

\section{Applications of nano-silver}

Nano-silver is the most studied and utilized nanoparticle for bio-system. It has been known to have strong inhibitory and bactericidal effects as well as a broad spectrum of antimicrobial activities. Silver nanoparticles, which have a high surface area and a high fraction of surface atoms, have a high antimicrobial effect as compared to bulk silver. In addition to this, Ag NPs have well-known recognition for their antioxidant, antibacterial, antifungal, anti-viral and antiinflammatory properties. It is highly mentioned that the use of Ag NPs in agriculture is mostly theoretical but in the near 
future researchers will get diverse applications of silver nanoparticles.

\subsection{Enhancement in plant growth}

Ag NPs have been used as a potential candidate to increase crop yield by enhancing seed germination and plant growth. The concentration of Ag nanoparticles (AgNPs) affects the growth response of plants with positive or negative impacts. Effect of Ag concentration on growth parameters of wheat, cowpea and Brassica are shown on Fig. 2 Specific concentrations of $\mathrm{Ag}$ nanoparticles have to be optimized. Effect of silver nanoparticles with diameters of $20 \mathrm{~nm}$ on seeds of Fenugreek (Trigonella foenum-graecum) has been carried out. ${ }^{\left[{ }^{[9]}\right.}$ Different concentrations of silver nanoparticles $(0,10$, 20,30 and $40 \mu \mathrm{g} \mathrm{mL}^{-1}$ ) were used and results showed that maximum seed germination $(76.11 \%)$, speed of germination (4.102), root length $(76.94 \mathrm{~mm})$, root fresh weight (2.783) and root dry weight (1.204) at a concentration of $10 \mu \mathrm{g} \mathrm{mL} \mathrm{L}^{-1}$. Exposure of plants to specific concentrations of AgNPs could promote plant growth as compared to non-exposed plants, whereas higher and lower concentrations could have an inhibitory effect on plant growth. ${ }^{[10]}$ The growth response of AgNPs using different concentrations $(0,25,50,100,200$ and $400 \mathrm{ppm}$ ) in brassica juncea and it is systematically concluded that 50-ppm treatment has been determined to be optimal with a positive effect on fresh weight, root and shoot length. ${ }^{[11]}$ Also, the concentration of AgNPs responsible for the observed effects for both cowpea and Brassica; in cowpea, $50 \mathrm{ppm}$ concentration resulted in growth promotion and increased root nodulation indirectly. ${ }^{[12]}$ These results revealed that application of silver nanoparticles could be used to significantly enhance seed germination potential, mean germination time, seed germination index, seed vigor index, seedling fresh weight and dry weight.

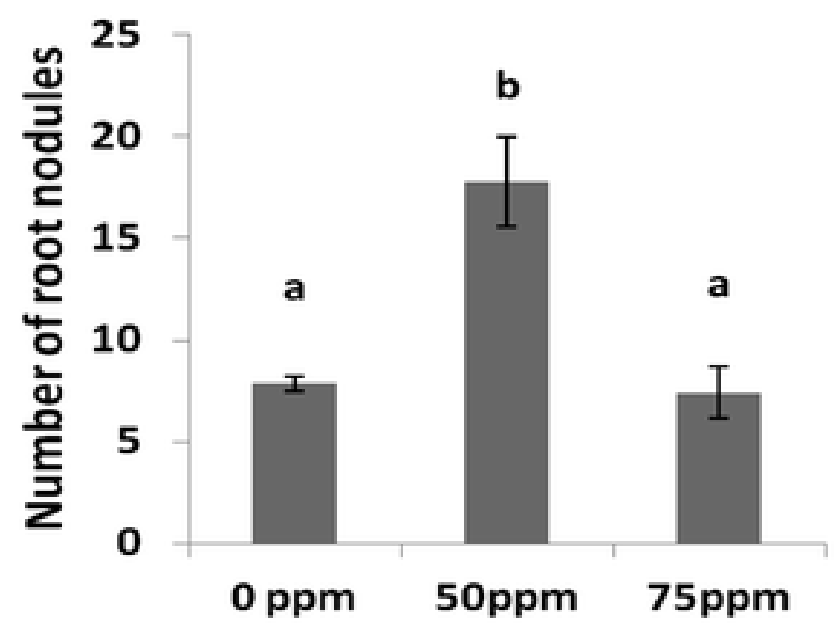

Fig. 2 Effect of Ag concentration on growth parameters of wheat, cowpea and brassica (reproduced with the permission from [12], copyright 2016, the author(s)).

\subsection{Plant disease management and crop protection}

Plant disease control in food crops and fruits is economically important and a needed research area. The well dispersed and stabilized, colloidal AgNPs are more adhesive on bacterial and fungal cell surface, hence act as better bactericide and fungicide. ${ }^{[13]}$ Fig. 3 shows the application of nanomaterials as the protectants or carriers to provide crop protection

Researchers formulated remarkable achievement in plant disease control with the application of AgNPs. DNA directed silver NPs grown on graphene oxide and studied the antibacterial activity against xanthomonas perforans, a causative agent of bacterial spot in Tomatoes. ${ }^{[14]}$ The antimicrobial activity of plant extract is due to the presence of secondary metabolites such as tannin, saponin, and glycosides. ${ }^{[15]}$ The in vitro antifungal activity of AgNPs against nineteen different plant pathogenic fungi is investigated. ${ }^{[16]}$ Cationic arginine gold nanoparticles (ArgNPs) assembled Cas9En (Etag)-RNP (ribonucleoproteins) delivery of sgRNA provides about $30 \%$ effective cytoplasmic/nuclear gene editing efficiency in cultured cell lines, which would greatly facilitate future research into crop development. ${ }^{[17]}$ The antifungal activity of silver nanoparticles synthesized by trichoderma longibrachiatum, against nine fungal isolates like aspergillus alternate and others. ${ }^{[18]}$

Bacterial diseases are one more cause of significant loss in crop yield worldwide. AgNPs are proved to be active against plant pathogenic bacteria. It is revealed that AgNPs have high antibacterial activity against erwinia cartovora, E. than generic antibiotics. ${ }^{[19]}$ They also studied the antifungal activity of AgNPs against pathogenic fungi viz. Fusarium oxysporum, alternaria alternata and aspergillus flavus and obtained promising results. Anti-fungal effectiveness of colloidal nano silver ( $1.5 \mathrm{~nm}$ average diameter) against rose powdery mildew caused by sphaerotheca pannosa var rosae. It is a very widespread and common disease of both greenhouse and outdoor grown roses. It causes leaf distortion, leaf curling, early defoliation and reduced flowering. Double capsulized nano silver was prepared by chemical reaction of silver ions with the aid of physical method, reducing agent and stabilizers. It eliminates unwanted microorganisms in planter soils and hydroponics systems. Moreover, silver is an excellent plantgrowth stimulator.

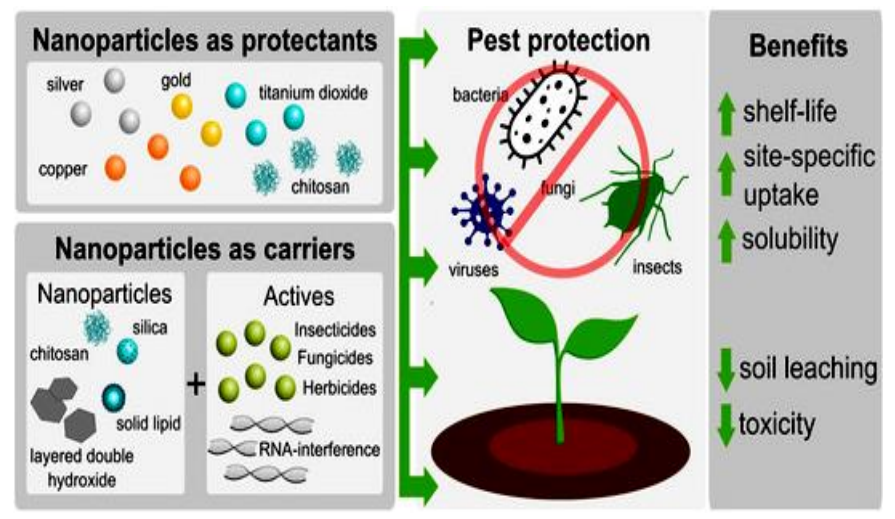

Fig. 3 nanomaterials as protectants or carriers to provide crop protection (reproduced with the permission from [12], copyright 2016, the author(s)). 


\subsection{Use as pesticides}

Silver nanoparticles have been experimented as pesticides to reduce the burden of pests from crops. It has a demand for pest protection and nutritional enrichment. This reduces frequent use of chemical fertilizers in conventional farming. It can destroy unwanted microorganisms in soils and hydroponics systems. As shown in Fig. 4, it is being used as foliar spray to stop fungi, moulds, rot and several other microbial associated plant diseases. ${ }^{[20,21]}$ Aqueous silver solution, used to treat plants, is reported to exhibit excellent preventive effects on pathogenic microorganisms causing powdery mildew or downy mildew in plants. Moreover, it promotes the physiological activity and growth of plants and induces disease and stress resistance in plants.

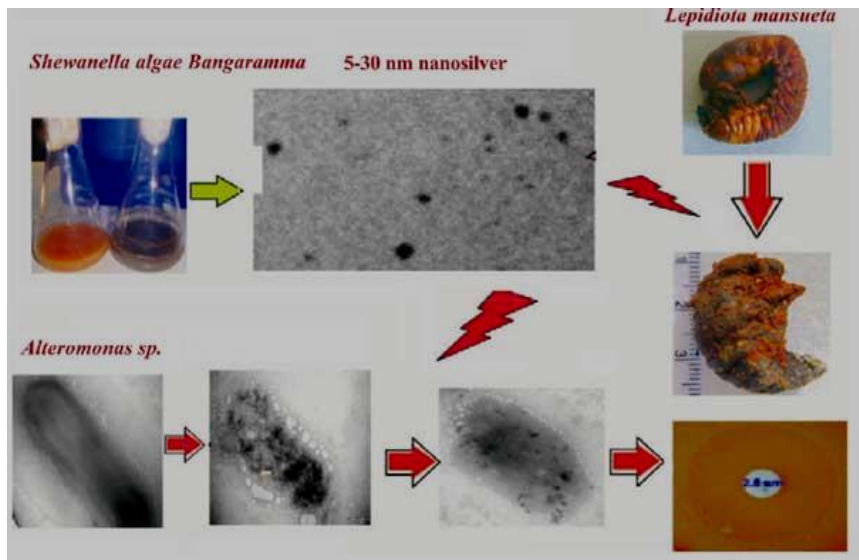

Fig. 4 Use of AgNP as foliar spray to stop microbial associated plant diseases (reproduced with the permission from [20], copyright Eureka Science (FZC)).

\subsection{Food packaging}

Post-harvest management, including the preservation of agricultural products, is one of the important branches of agriculture. Previous studies have reported that AgNPs based antimicrobial packaging plays an important role in increasing the shelf life of fresh fruits and vegetables. ${ }^{[22]}$ Fig. 5 gives a brief idea about application of the AgNPs in food packaging. The effect of AgNPs-PVP coating on preservation of green asparagus is studied successfully. ${ }^{[23]}$ It is observed that coating of AgNPs PVP slowed down the weight loss, ascorbic acid and total chlorophyll, reduced the color changes in the skin of asparagus, inhibited the increasing of the tissue firmness, the growth of microorganism and increased the shelf-life of asparagus by about 10 days at $2{ }^{\circ} \mathrm{C}$. Similarly, the preservation of vegetable and fruits using biosynthesized AgNPs is examined by Fayaz et al..$^{[24]}$

The preparation of AgNPs incorporated sodium alginate films is carried out and studied its antibacterial activity, measured weight loss (\%) of fruits and vegetables, and performed sensory analysis. The minimum weight loss was observed in AgNPs incorporated sodium alginate film coated carrots and pears compared to sodium alginate coated and uncoated control. The color, appearance, texture and taste of AgNPs incorporated sodium alginate film coated carrots and pears were found to be acceptable up to 10 days of storage as compared to uncoated control and sodium alginate coated carrots and pears. Low density polyethylene (LDPE) polymer matrix containing AgNPs was studied to preserve and extend the shelf life of stored barberries. ${ }^{[25]}$ Nano packaging with AgNPs-LDPE successfully maintained the sensory, physicochemical and physiological qualities of barberry and strawberry fruits at a higher level compared with normal packaging with polyethylene bags.

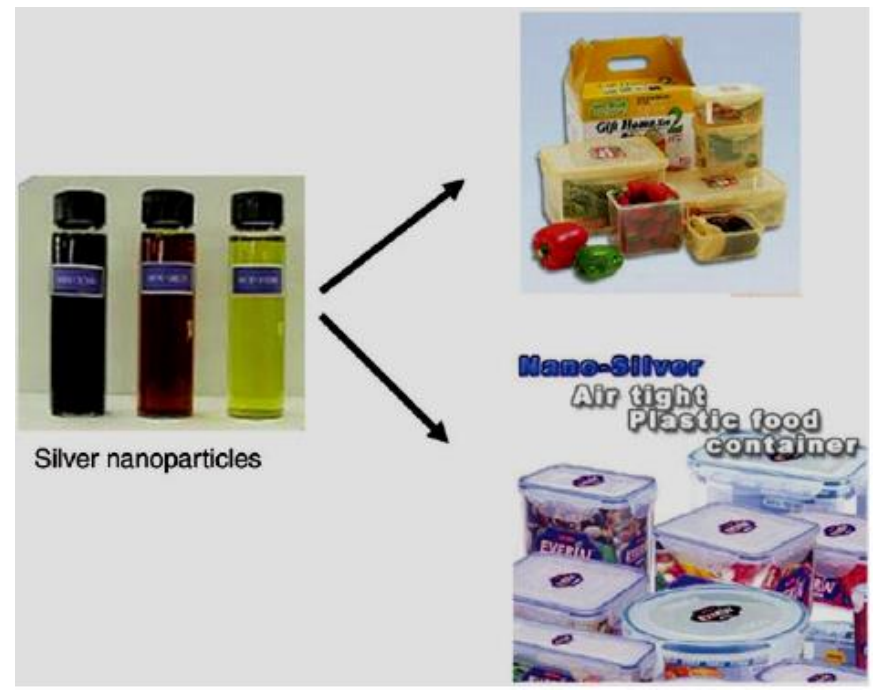

Fig. 5 Application of AgNP in food packaging (reproduced with the permission from [22], copyright 2007 Swiss Society of Food Science and Technology).

\subsection{Pest management}

It is possible to control pests by incorporating nanoparticles into them. Nano-silver serves as an efficient pest management agent that is non-toxic, safe and an enhanced pest control tool, and the silver nanoparticle-based pesticide also provides high dose of pesticides to the target plants. ${ }^{[26,27]}$ The pesticide activity of silver nanoparticles can help a lot in the control of pests, because in the green method of preparation of silver nanoparticles, The biological agents used for their synthesis may be microbes or plants and the flavonoids present in the plants prove to be toxic to the plants. ${ }^{[28]}$ Use of AgNPs in insect pest management has been reported. ${ }^{[29]} \mathrm{AgNPs}$ are used in the control of disease in rice weevils and grasserie. AgNPs treated stored rice remained uninfected even after 2 months of treatment, so it is suggested that Ag NPs can also be used as an excellent seed protecting agent.

\section{Conclusions and future scope}

Nanotechnology is a promising technology with the ability to create massive changes in the agricultural sector. It is becoming progressively important for the agribusiness. AgNPs are recognized as potential candidates in agriculture by exhibiting remarkable characteristics. AgNP successfully used to increase crop yield, protect the crop from bacterial, fungal infections/diseases and pest attack/infestation. Additionally, AgNPs are employed in the form of 'nano- 
packages' to increase the shelf life of fresh agricultural produce like fruits and vegetables. Now, there is a need for research on assessment of AgNPs actual impact on the environment and human health before mass production and use of agricultural applications.

Even though nanotechnology is an emerging field of science greatly exploited in different sectors mainly electronics, energy, environment and health, its application in agriculture is rarely exploited in India and abroad though it has tremendous potential as a new effective tool in the agricultural field to gain solutions to unresolved field problems. This new technology will be helpful in markets economically. The research in this sector in India is still at a preliminary stage and also at a conceptual level to understand realistic assessments. Our farmers should benefit from such innovative use in farming, then only we can recognize the utilization of nanoparticles in social aspects. Researchers in the nanotechnology sector have wide scope to utilize prepared nanoparticles for agriculture applications in a smart way.

\section{Acknowledgement}

Authors would like to thank Pimpri Chinchwad College of Engineering, Pune for providing infrastructural facilities to complete the present article.

\section{Conflict of Interest}

There is no conflict of interest.

\section{Supporting Information}

Not Applicable

\section{References:}

[1] S. K. Kulkarni, Nanotechnology: principles and practices, Springer, 2014, doi: 10.1007/978-3-319-09171-6

[2] N. Scott, H. Chen, Industrial Biotechnology, 2013, 9, 17-18, doi: 10.1089/ind.2013.1555.

[3] K. V. Prasad, P. Sudhakar, Y. Sreenivasulu, Journal of Plant Nutrition, 2012, 35, 905-927, doi: 10.1080/01904167.2012.663443.

[4] M. C. DeRosa, C. Monreal, M. Schnitzer, R. Walsh, Y. Sultan, Nature Nanotechnolgy, 2010, 5, 91, doi: 10.1038/nnano.2010.2.

[5] M. Delfani, M. Baradarn Firouzabadi, N. Farrokhi, H. Makarian, Communications in Soil Science Plant Analysis, 2014, 45, 530-540, doi: 10.1080/00103624.2013.863911.

[6] R. E. Smolker, The environmental defense fund, Biological Convervation, 1968, 1, 69-70, doi: 10.1016/00063207\%2868\%2990023-2.

[7] R. Y. Parikh, S. Singh, B. L. V. Prasad, M. S. Patole, M. Sastry, Y. S. Shouche, ChemBioChem, 2008, 9, 1415-1422, doi: 10.1002/cbic. 200700592.

[8] S. S. Hojjat, International Journal of Agriculture and Crop Science, 2015, 8, 627-630.

[9] G. Sathishkumar, C. Gobinath, K. Karpagam, V. Hemamalini, K. Premkumar, S. Sivaramakrishnan, Colloids and Surfaces B: Biointerfaces, 2012, 95, 235-240, doi: 10.1016/j.colsurfb.2012.03.001.

[10] P. Sharma, D. Bhatt, M. G. H. Zaidi, P. P. Saradhi, P. K.
Khanna, S. Arora, Applied Biochemistry and Biotechnology, 2012, 167, 2225-2233, doi: 10.1007/s12010-012-9759-8.

[11] H. Joshi, Somdutt, P. Choudhary, S. L. Mundra, International Journal of Chemical Studies, 2019, 7, 957-963.

[12] C. M. Pallavi, Biotech, 2016, 6, 254, doi: 10.1007/s13205016-0567-7.

[13] I. Ocsoy, M. L. Paret, M. A. Ocsoy, S. Kunwar, T. Chen, M. You, W. Tan, ACS Nano, 2013, 7, 8972-8980, doi: $10.1021 / \mathrm{nn} 4034794$.

[14] S. A. Polash, T. Saha, M. S. Hossain, S. R. Sarker, Journal of Advances in Biology Biotechnology, 2017, 8, 149-162, doi: 10.4236/abb.2017.85012.

[15] S. W. Kim, J. H. Jung, K. Lamsal, Y. S. Kim, J. S. Min, Y. S. Lee, Mycobiology, 2012, 40, 53-58, doi: 10.5941/myco.2012.40.1.053

[16] R. Mout, M. Ray, G. Yesilbag Tonga, Y.-W. Lee, T. Tay, K. Sasaki, V. M. Rotello, ACS Nano, 2017, 11, 2452-2458, doi: 10.1021/acsnano.6b07600.

[17] R. M. Elamawi, R. E. Al-Harbi, A. A. Hendi, Egyptian Journal of Biological Pest Control., 2018, 28, 28, doi: 10.1186/s41938-018-0028-1.

[18] N. Y. Nadaf, S. S. Kanase, Digest Journal of Nanomaterials and Biostructures, 2015, 10, 1189-1199.

[19] B. Alloway, Micronutrient deficiencies in global crop production, Springer, 2008, doi: 10.1007/978-1-4020-6860-7.

[20] M. Y. Babu, V. J. Devi, C. M. Ramakritinan, R. Umarani, N. Taredahalli, Current Nanoscience, 2014, 10, 374-381, doi: 10.2174/15734137113096660103.

[21] M. Rai, S. Birla, A. P. Ingle, I. Gupta, A. Gade, K. AbdElsalam, P. D. Marcato, N. Duran, Nanotechnology Review, 2014, 3, 281-309, doi: 10.1515/ntrev-2014-0001.

[22] J. An, M. Zhang, S. Wang, J. Tang, LWT - Food Science and Technology, 2008, 41, 1100-1107, doi: 10.1016/j.lwt.2007.06.019. [23] A. Mohammed Fayaz, K. Balaji, M. Girilal, P. T. Kalaichelvan, R. Venkatesan, Journal of Agricultural and Food Chemistry, 2009, 57, 6246-6252, doi: 10.1021/j9900337h.

[24] S. Soleimanian-Zad, Innovative Food Science Emerging Technologies, 2010, 11, 742-748, doi: 10.1016/j.ifset.2010.06.003

[25] N. Valipoor Motlagh, M. T. Hamed Mosavian, S. A. Mortazavi, Packaging Technology and Science, 2013, 26, 39-49, doi: $10.1002 /$ pts. 1966 .

[26] K. Lamsal, S.-W. Kim, J. H. Jung, Y. S. Kim, K. S. Kim, Y. S. Lee, Mycobiology, 2011, 39, 26, doi: 10.4489/myco.2011.39.1.026.

[27] M. Ragaei, A. Hasaan Sabry, International Journal of Environmental Science and Technology, 2014 3, 528-545.

[28] A. A. Zahir, A. Bagavan, C. Kamaraj, Journal of Biopesticides, 2012, 5, 95-102.

[29] S. Routray, D. Dey, S. Baral, A. P. Das, V. Patil, Progressive Research An International Journal, 2016, 11, 903-906.

\section{Author information}

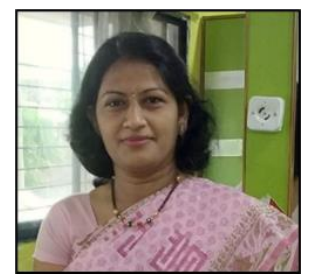

Sonali Kiran Kale is Assistant Professor in Physics at the First Year Department, Pimpri Chinchwad College of Engineering, Nigdi, Pune. She completed Ph.d. in Material Science, Nanotechnology from the Department of Physics, Savitribai Phule University, Pune in 2008. She joined 
National Chemical Laboratory (NCL), Pune for her postdoc research in 2010. Dr. Kale has strong research experience in material preparation and its characterizations. She is pursuing her research interest in preparation, characterizations and Applications of Nanomaterials in Energy and Agriculture. She has quality journal publications in international journals and takes efforts to perform research projects as well. She is always guiding her undergraduate, postgraduate engineering students in innovative projects.

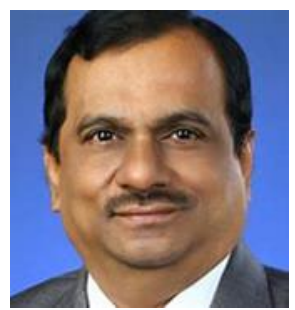

Gajanan Vaijanath Parishwad,

Principal, Pimpri-Chinchwad College of Engineering, Akurdi, Pune. Dr. Parishwas is dedicated to academics and research enthusiastically. He is expert in research areas like solar energy, nanomaterials, applications of nanomaterials in thermal management, Dr. Parishwad has prestigious National awards on his name. He is guiding and motivating, always guiding faculty, undergraduate, postgraduate engineering students for pursuing quality research. Sir has quality research publications in international journals, conferences and guiding research students as well.

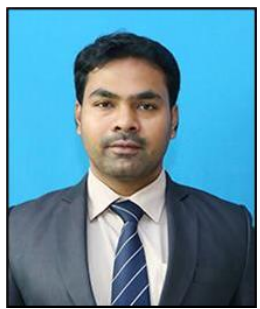

Avesahemad Husainy is Assistant Professor in Mechanical Engineering at Sharad Institute of Technology College of Engineering, Yadrav, Sangli, Maharashtra, India. He is pursuing his Ph.D. at Shivaji University, Kolhapur. Research interests of Mr. Husainy are Refrigeration, Air conditioning, Applications of nanoparticles-Phase change materials in agriculture sector, energy domain. He is very always enthusiastic to guide graduates and post graduates engineers in innovative projects and utilizing his research skills at societal aspects. He has quality journal publications in international journals and takes efforts to perform research projects successfully.

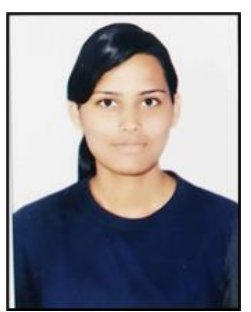

Aishwarya Sanjay Patil pursuing MTech in Mechanical and Materials from Savitribai Phule Pune University and my area of research is Nanomaterials and $I$ am currently working on Phase change Materials (PCM) and its applications in the Refrigeration industry.

Publisher's Note: Engineered Science Publisher remains neutral with regard to jurisdictional claims in published maps and institutional affiliations. 